\title{
Factors Predicting Falls in Parkinson's Disease: Investigation of Motor, Non-motor Findings and Different Dual Task Activities
}

Parkinson Hastalı̆̆ında Düşmeyi Öngördüren Faktörler: Motor ve Non-motor Bulgular ile Farklı Çift Görev Aktivitelerinin Birlikte İncelenmesi

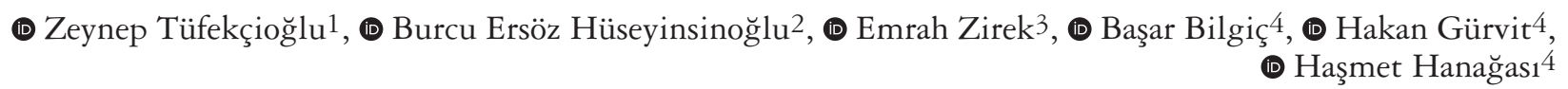

1 Istanbul Aydın University, Department of Neurology, Istanbul, Turkey

2Istanbul University-Cerrahpasa, Cerrahpasa Faculty of Health Sciences, Department of Physiotherapy and Rehabilitation, Istanbul, Turkey

3Bingol University Faculty of Health Sciences, Department of Physiotherapy and Rehabilitation, Bingol, Turkey

${ }^{4}$ Istanbul University Istanbul Faculty of Medicine, Department of Neurology, Behavioral Neurology and Movement Disorders Unit, Istanbul, Turkey

\begin{abstract}
Objective: The purpose of this study was to identify the predictors of future falls in mild-to-moderate stage Parkinson's disease (PD) without cognitive impairment. We evaluated motor findings, non-motor findings, and different cognitive dual tasks such as memory, attention, and executive functions added to the 10-meter walk test (10MWT), which has been used to measure walking speed in PD.

Materials and Methods: A total of 62 subjects were evaluated in terms of eligibility for the study. Thirty-six patients with PD who met the inclusion criteria were included in the study. Demographic characteristics were identified and clinical findings were examined. Motor and non-motor findings were evaluated using the Turkish version of the Movement Disorder Society-Unified PD Rating scale (MDS-UPDRS). Walking speed was measured with the 10MWT as single task and with different cognitive domains added to the 10MWT as cognitive dual task activities. After the initial evaluation, falls within six months were recorded.

Results: The previous history of falls, high scores of MDS-UPDRS 1.A, MDS-UPDRS 1.B, and MDS-UPDRS 2, walking speed under a single task (10MWT) and different cognitive (memory, digit span-forwards, digit span-backwards, and serial 7s) dual tasks were significantly different in terms of the future falls within six months $(\mathrm{p}<0.05)$. According to the results of multiple logistic regression analysis using these variables, it was observed that the increase in 10MWT speed decreased the risk of future falls by 0.76 times, and an increase in MDS-UPDS 1.B score increased the risk of future falls by 2.06 times.

Conclusion: In our study, in which the known risk factors associated with falls in PD were examined together, the risk of falls in patients with mild-to-moderate stage PD without cognitive impairment was found to be predicted by gait speed and the MDS-UPDRS 1.B score, which evaluated non-motor findings such as sleep disorder, sensory problems, and autonomic dysfunction.
\end{abstract}

Keywords: Falls, Parkinson's disease, non-motor, dual task

$\ddot{O} \mathbf{z}$

Amaç: Bu çalışmada, kognitif bozukluğu olmayan erken-orta evre Parkinson hastalığı (PH) olan hastalarda, düşme için risk faktörü olarak daha önceki çalı̧̧malarda belirlenmiş motor bulgular ile PH'de yürüme hızının ölçülmesinde kullanılan on metre yürüme testine (10MYT) eklenen bellek, basit dikkat ve karmaşık dikkat kognitif çift görev aktivitelerinin ve PH'nin non-motor bulgularının hangilerinin gelecekteki düşmeyi daha iyi tahmin ettireceğinin araştırılması amaçlanmışıı. Gereç ve Yöntem: Çalışmaya dahil edilmek üzere 62 kişi değerlendirildi. Dahil edilme kriterlerine uyan 36 kişi çalışmaya alındı. Olguların demografik özellikleri ve klinik bulguları sorgulandı. Motor ve non-motor bulgular Hareket Bozuklukları Derneği Birleşik PH Derecelendirme ölçeği Türkçe versiyonu (HBD-BPDHÖ) ile değerlendirildi. Yürüme hızı 10MYT ve 10MYT’ye eklenen farklı kognitif çift görev aktiviteleri kullanılarak ölçüldü. İlk değerlendirmeden sonra altı ay içindeki düşme hikayesi kaydedildi.

Bulgular: Olguların önceki düşme öyküsünün olması, HBD-BPHDÖ 1.A, HBD-BPHDÖ 1.B ve HBD-BPHDÖ 2 skorlarının yüksek olması, 10MYT (tek görev) hızı ile 10MYT bellek, ileri ve geri sayı menzili ve yürütücü işlev çift görev aktiviteleri hızlarının daha düşük olması, altı ay içinde düşme meydana gelmesi ile anlamlı olarak ilişkiliydi $(\mathrm{p}<0,05)$. Bu değişkenler kullanılarak yapılan çoklu lojistik regresyon analizi sonucuna göre; hastaların altı ay içinde düşme riskini 10MYT hızındaki artışın 0,76 kat azalttı̆̆

Address for Correspondence/Yazışma Adresi: Zeynep Tüfekçioğlu MD, Istanbul Aydın University, Department of Neurology, Istanbul, Turkey Phone: +90 5304012844 E-mail: tufekcioglu.z@gmail.com ORCID: orcid.org/0000-0001-6989-8611

Received/Geliş Tarihi: 09.08.2019 Accepted/Kabul Tarihi: 11.11.2019

${ }^{\circ}$ Copyright 2020 by Turkish Neurological Society

Turkish Journal of Neurology published by Galenos Publishing House. 


\section{$\ddot{O} \mathbf{z}$}

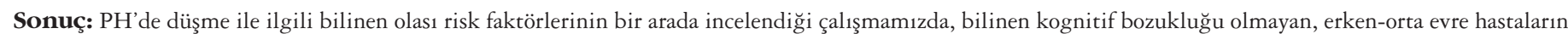

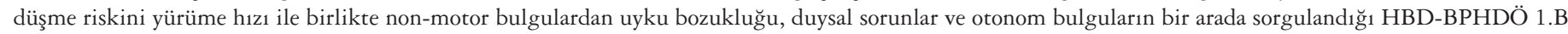
skorunun öngördüğ̈̈ bulunmuştur. Bu bulguların desteklenebilmesi için daha geniş hasta popülasyonunda daha uzun takipli çalışmalar gerekmektedir.

Anahtar Kelimeler: Düşme, Parkinson hastalığı, non-motor, çift görev

\section{Introduction}

Falling is one of the most important causes of morbidity in Parkinson's disease (PD) (1). Approximately 60\% of patients with PD fall at least once every year (2), and falls recur in at least one-third of these patients (3). Although it is very important in terms of public health to reduce the risk of falling in PD because of injuries, decreased independence, decreased quality of life, lack of self-confidence, and increased health expenses, protection approaches against falling are not enough (4).

Falling in PD occurs as a result of a complex interaction of many factors, not all of which have been explained (4). Although many risk factors have been suggested to date, including general and PD-related risk factors, none of them alone can predict falling (5). Due to these limitations, it is still not possible to prevent or treat falls completely (6). The PD-associated risk factors of falling that have been investigated and predicted to date are more likely to involve motor impairments, but studies on the relationship between non-motor findings and the risk of falling are more limited.

Prospective studies have shown that the motor manifestations seen in PD including freezing $(7,8)$, decreased mobility (7), imbalance $(7,8)$, decreased leg strength $(8)$, disease severity, and previous fall history $(1,2,8)$ can predict future falls. For a practical approach, in a study in which these risk factors were taken into consideration, a simple formula that predicted falls was developed (9). According to this formula, the previous fall history, freezing, and a decrease in walking speed are factors that best predict falls that may occur in the future, and according to the severity of these findings, patients can be classified as having low, medium or high risk for falling.

In addition to the deterioration of automatic motor movements such as walking and standing in PD (10), cognitive functions such as attention (11) and executive functions are deteriorated and patients with PD, compared with normal controls, have difficulty in dual tasks that need to be performed simultaneously such as looking at a mobile phone while walking or counting while walking (12), their walking speeds slow down and risk of falling increases $(13,14)$. Based on these studies, the difficulty in performing a second task added to walking is also among the risk factors of PD-related falls (6). However, while the previous fall history has been associated with cognitive dual task activity in these studies, studies on predicting future falls are limited.

Cognitive impairment has been the most investigated risk factor, which was found to be a risk factor for falling in prospective studies among non-motor findings such as cognitive, psychiatric disorders, sensory, and sleep and autonomic disturbances accompanying motor findings in PD $(8,15)$. There are a limited number of studies on other non-motor findings such as depression and anxiety disorder, and the number of samples is more limited
$(16,17)$. It has been shown that excessive daytime sleepiness is associated with the risk of falling in both the general population and patients with PD (18). Among the autonomic findings, orthostatic hypotension is among the general risk factors. It has been investigated in a small number of studies on PD and has not been found as an independent risk factor alone $(8,19)$. It has been shown that drugs used to treat urinary incontinence posed a risk of falling, and that it alone was an important risk factor for falling in both the geriatric population and patients with $\operatorname{PD}(3,20)$.

In a recently published review, it was emphasized that motor and non-motor findings, which are in complex interaction, should be evaluated together (21). However, in the literature, an evaluation system that predicts falling that includes all these findings has not been established.

This prospective study investigated which of the following would better predict future falls in patients with early-to-midstage PD: motor findings, identified in previous studies as a risk factor for falling; the 10-minute walk test (10MWT), commonly used to measure walking speed in patients with PD; memory, simple attention, and complex attention cognitive dual task activities; and non-motor findings of PD (22).

\section{Materials and Methods}

\section{Patient Selection}

In this descriptive study, of the patients who were consecutively admitted to the Movement Disorders Outpatient Clinic of Istanbul Medipol University Medical Faculty Department of Neurology, Behavioral Neurology and Movement Disorders Unit between 30.12.2015-09.05.2017, were diagnosed as having PD according to the United States (US) PD Society Brain Bank Clinical Diagnostic Criteria (23), and whose medical treatment continued, 36 who met the inclusion criteria were included in the study.

The study plan was approved scientifically and ethically in a meeting of the Istanbul Medipol University, Non-Interventional Clinical Research Ethics Committee (date: 23.12.2015). All patients included in the study were informed about the purpose and duration of the study and the evaluations that would be performed in the study. All patients were included in the study after signing the "Informed Volunteer Consent Form" approved by the Istanbul Medipol University Non-Interventional Clinical Research Ethics Committee.

\section{Inclusion and Exclusion Criteria}

In our study, it was planned to include patients who had no cognitive impairment in order to fulfill the cognitive loads to be used while evaluating the double-task activity, had an education level of at least five years, could walk alone in order to fulfill the 
10MWT, did not have frequent freezes, and did not have impaired balance. Patients who were diagnosed as having PD according to the US PD Society Brain Bank Clinical Diagnostic Criteria (23), had stage 1-3 disease according to the Hoehn-Yahr scale, who scored 21 or above from the Montreal Cognitive Assessment (MoCA) $(24,25)$, scored $0-3(\leq 3)$ from the $3^{\text {rd }}$ item of the Freezing of Gait Questionnaire $(26,27)$, scored $31.75 \mathrm{~cm}$ or above in the Functional Reach test (FRT) $(28,29)$, and had no visual and auditory problems were included in the study. Patients with known dementia, major depression or psychiatric problems, any cardiac or orthopedic problems affecting walking, any neurologic problems other than PD, and an education level less than 5 years were excluded.

\section{Demographic Data of the Patients}

The name, surname, sex, age, profession, dominant extremity, educational background, medical history, family history, disease duration, treatment history, medication use, and fall history in the last 6 months were questioned in patients who voluntarily participated in the study. Levodopa equivalent doses of the drugs used were calculated (30). Patients were called by phone 6 months after the initial evaluation and questioned as to whether they had fallen in the last 6 months.

\section{Scales Used}

All evaluations in the study were made in the "on" period of the patients. Various scales were administered to the patients in order to determine their suitability for the inclusion criteria before they were evaluated for walking. The Hoehn-Yahr scale was used to determine the severity of the disease, and early and mid-stage patients were included in the study. The third question of the Turkish version of the Freezing of Gait Questionnaire was used because it was a good method to evaluate the frequency of freezing that occured during walking (26,27,31). In this test, each question gets a value between " 0 " and " 4 " and the worst case is scored as " 4 ". The third question is related to the frequency of freezing. Patients with constant freezing who scored 4 points from this question were excluded from the study. The FRT, which has been widely used for balance assessment, was used in our study (28). In this test, the arm is raised to shoulder level while standing still and the patient stretches forward as far as possible without disturbing the fixed posture and the distance reached is calculated. The cut-off score for PD is $31.75 \mathrm{~cm}$ (29). Patients who could not reach the specified distance were not included in the study. The clinical features of the patients were evaluated using the Turkish version of the Movement Disorder Society Unified PD Rating scale (MDSUPDRS), where the motor and non-motor features of the disease were scored according to the data obtained from the interviews with patients or patient relatives and from the examination findings (32). This test comprises 4 separate sections. The first section is about non-motor problems. The first 6 questions in this section are referred to as "part 1.A" and are related to cognitive involvement, hallucinations and psychosis, depression, anxiety, apathy, and dopamine dysregulation syndrome. The next 6 questions constitute "part 1.B" and are related to sleep problems, daytime sleepiness, pa,in and other sensory problems, urinary problems, constipation, orthostasis, and weakness. The second section questions motor problems such as speaking, saliva flow from the mouth, chewing and swallowing, eating, dressing, personal cleaning, writing, hobbies and other activities, turning in bed, tremor, getting out of bed/getting out of car/ getting up from a low chair, walking, balance, and freezing. The third section is where the motor problems of the patient are evaluated by the physician. In the fourth section, motor complications are questioned. Each question is scored between 0 and 4 for. "0" means normal and " 4 " is interpreted as severe. A high total score in the test means that the stage of illness is high. In order to evaluate cognitive functions, the Turkish version of the MoCA test, which evaluates different cognitive areas was used in individuals with PD. The Turkish validity and reliability study has been performed $(24,25)$. In this test, where the highest score is 30 , the cognitive impairment limit in our country is below 21. Therefore, patients with a MoCA score of 21 or above were included in the study. Patients with dementia and major depression or psychiatric problems were excluded.

The walking speed of the patients who met the criteria for participation in the study was evaluated using the 10MWT. In this test, the first and last 2-meter sections of the 10 meter distance, which has pre-determined starting and ending points, are marked. Participants are asked to start walking at their normal speed when their toes are at the line of 0 metres and to stop after crossing the line at 10 metres. The evaluation starts from the first step that crosses the $2^{\text {nd }}$ meter and ends in the first step that exceeds the 8 th meter. The result is recorded in meters per second $(\mathrm{m} / \mathrm{s})(33,34)$.

\section{Dual-task Activity Walk Protocol}

In the dual task evaluation of the subjects, the cognitive tasks added to the 10MWT included delayed memory, digit spanforwards (5 digits), digit span-backwards (3 digits), and complex attention function (counting by subtracting 7 from 100). For these cognitive activities, the memory and attention sections of MoCA, a standardized test, were used, and the speed of completion of the 10MWT by patient was recorded for each pair of added task activities. According to this protocol, the patients were evaluated in the following order under five walking conditions.

1. 10MWT (Single Task): The participant was asked to walk 10 meters at normal speed.

2. 10MWT + Cognitive Task 1/Memory (Dual Task): The participant was asked to remember five words that were told and repeated 10 minutes ago and repeat them once in an audible manner (nose, velvet, mosque, daisy, purple) while walking the 10-meter path at normal speed.

3. 10MWT + Cognitive Task 2/Digit Span-forwards (Dual Task): The participant was asked to repeat the 5 numbers (21854), which were told just before walking, at once and in the same order while walking the 10 -meter path at normal speed.

4. 10MWT + Cognitive Task 3/ Digit Span-backwards (Dual Task): The participant was asked to repeat the 3 numbers (742), which were told just before walking, at once in an audible manner and from the end to the beginning while walking the 10 -meter path at normal speed.

5. 10MWT + Cognitive Task 4/(100-7) (Dual Task): The participant was asked to count in series, subtracting 7 from 100 , at the same time as walking the 10-meter path at normal speed. 


\section{Statistical Analysis}

The Statistical Package for the Social Sciences (SPSS) Version 21.0 (SPSS Inc., Chicago, IL, USA) package program was used for statistical analysis of the study data. The KolmogorovSmirnov test was used to reveal whether the data showed normal distribution. Parametric tests were used to analyze data with normal distribution, and non-parametric tests were used to analyze data without normal distribution. In the statistical analysis of the study, variables were defined by mean, standard deviation, median, minimum and maximum values. Independent categorical data were evaluated using the chi-square test and Fisher's exact test. The independent groups t-test was used to evaluate 2-group numerical data with normal distribution, and the Mann-Whitney $U$ test was used in cases where there was no normal distribution. In all tests, $\mathrm{p}<0.05$ was accepted as the limit for statistical significance. Logistic regression analysis was performed to find out how many of the independent variables that were found to statistically related with falls could predict falling together. The compatibility of the models in the logistic regression analysis was evaluated by whether p was $>0.05$ in the Hosmer-Lemeshow test.

\section{Results}

Sixty-two patients were evaluated for inclusion in the study. Of these patients, four patients who refused to participate in the 10MWT, nine patients whose MoCA scores were below 21 points, six patients whose education years were below 5 years, two patients who scored $>3$ from the third item of the Freezing of Gait Questionnaire, and five patients whose follow-up information about falling was not obtained, a total of 26 patients were excluded from the study, and 36 patients were included in the study.

The demographic information and clinical characteristics of the patients included in the study are shown in Table 1 . There were no statistically significant differences in terms of age and sex between the patients who did and did not fall within six months of the start of the study. The duration of the disease and the equivalent doses of Levodopa used were similar in both groups. The Hoehn-Yahr score showing disease severity, the MDS-UPDRS 3 score showing measurable motor findings of the disease, and the MDS-UPDRS 4 score showing motor complications did not differ significantly between the two groups, whereas the MDS-UPDRS 1.A and 1.B scores showing non-motor findings and the MDS-UPDRS 2 scores showing motor findings were significantly different between the two groups. There were statistically significant differences between the 10MWT completion speed of the single task used to measure the walking speed of the patients and the completion speeds of each of the cognitive dual tasks added to this test. MoCA scores of these patients with no known cognitive complaints did not differ between the two groups (Table 1).

Having a previous fall history, higher MDS-UPDRS 1.A, MDSUPDRS 1.B, and MDS-UPDRS 2 scores, lower 10MWT (single task) speed, lower speed of 10MWT memory, digit span-forwards and backwards, and (100-7) dual task activities were significantly related with falling within six months (Table 1). Data showing

Table 1. Demographic and clinical characteristics of the patients

\begin{tabular}{|c|c|c|c|}
\hline Variables & $\begin{array}{l}\text { Patients who fell within } 6 \text { months } \\
(\mathrm{n}=22)\end{array}$ & $\begin{array}{l}\text { Patients who did not fall } \\
\text { within } 6 \text { months }(n=14)^{*}\end{array}$ & $\mathrm{p}$ \\
\hline Age, year (SD) & $61(1.12)$ & $65.92(2.21)$ & $0.062^{\dagger}$ \\
\hline Disease duration, year & $5.95(1.00)$ & $7.85(1.64)$ & $0.330^{\dagger}$ \\
\hline Levodopa equivalent dose (mg) & $786.10(92.96)$ & $933.45(221.36)$ & $0.549 \dagger$ \\
\hline MoCA score & $25.90(0.43)$ & $25.35(0.60)$ & $0.442 \S$ \\
\hline FGQ 3 score & $0.86(0.21)$ & $1.57(0.32)$ & $0.072 \S$ \\
\hline MDS-UPDRS 1.A & $3.27(0.67)$ & $6.28(1.24)$ & $0.019 \S$ \\
\hline MDS-UPDRS 1.B & $6.09(0.67)$ & $11.42(1.15)$ & $0.001 \S$ \\
\hline MDS-UPDRS 2 & $10(1.06)$ & $15.57(2.57)$ & $0.051 \S$ \\
\hline 10MWT speed $(\mathrm{m} / \mathrm{s})$ & $0.93(0.05)$ & $0.64(0.03)$ & $<0.00^{\dagger}$ \\
\hline 10MWT + memory speed $(\mathrm{m} / \mathrm{s})$ & $0.84(0.05)$ & $0.59(0.03)$ & $<0.001^{\dagger}$ \\
\hline 10MWT + digit span-forwards speed (m/s) & $0.87(0.06)$ & $0.64(0.04)$ & $0.005^{\dagger}$ \\
\hline 10MWT + digit span-backwards speed $(\mathrm{m} / \mathrm{s})$ & $0.90(0.05)$ & $0.67(0.04)$ & $0.004^{\dagger}$ \\
\hline $10 \mathrm{MWT}+(100-7)$ speed $(\mathrm{m} / \mathrm{s})$ & $0.76(0.04)$ & $0.55(0.04)$ & $0.003^{\dagger}$ \\
\hline
\end{tabular}


significant changes in single variable analysis were included in logistic regression analysis in order to find the model that best predicted falling within 6 months. Table 2 shows the results regarding the univariate logistic regression models of the variables that may be related to falling within six months. As a result of the likelihood ratio test, the variables whose probability level (p) given in Table 2 were below $0.25(\mathrm{p}<0.25)$ were determined as candidate variables for the multivariate model (35).

As a second step, the selection of candidate variables that were considered to be included in the model was made using the backward elimination method based on likelihood ratio test statistics, which was one of the stepwise selection methods, and G statistics were calculated for the significance tests. The likelihood ratio test statistics $(\mathrm{G})$ value comparing models with and without an independent variable was equal to the difference of the -2loglikelihood values of these two models. Independent variables with significance below $\mathrm{p}<0.05$ were included in the model. The results obtained regarding the logistics model are given in Table 3. As can be seen in Table 3, 10MWT speed and MDS-UPDRS 1.B scores contributed significantly to predicting the possibility of patients falling within 6 months. Accordingly, when the 10MWT speed of the patients increased by one unit, the probability of falling within six months decreased by 0.76 times, and a one unit increase in MDS-UPDRS 1.B score increased the probability of falling within six months by 2.06 times. The sensitivity level of this prediction model with two independent variables was $12 /(12+2)=0.86$, and the specificity level was $20 /(20+2)=0.91$ (Table 3 ).

\section{Discussion}

Falling, which is one of the leading causes of morbidity in PD, is observed in patients with moderate-severe stage disease, whose mobility is gradually restricted, disease severity is increased, and cognitive problems are added. However, recent studies have shown that there may be falls in mild stage and even prodromal stage PD $(4,36,37)$. Although the risk of falling in these studies was associated with age, quality of life, and previous history of falling, no extensive risk screening was performed. In another study consisting of relatively young patients with PD who had no previous history of falling, the factors that determined the first fall were shown to be walking speed, standing time, and HoehnYahr scale score (38). It is known that motor or cognitive dual task activity slows down walking speed and increases the risk of falling in PD (39). However, in patients with early-stage disease, studies that predict falling, especially with different cognitive dual task activities, are limited $(12,13,14)$. In a recent review, it was emphasized that because of the complex pathophysiology and rich clinical findings of $\mathrm{PD}$, motor/non-motor findings should be evaluated together while estimating risk for falls $(6,21)$. However, according to our knowledge, to date, no study has evaluated motor/non-motor findings and different cognitive dual task activities in predicting future falls. For this reason, in our study, it was aimed to determine the independent risk factors that would cause falls by comprehensively evaluating motor and non-motor clinical features and walking under four different cognitive tasks in patients with mild-moderate PD. For this purpose, the patients were divided into two groups according to whether had or had not fallen within 6 months after the first evaluation. There were no differences between the two groups in terms of age, duration of disease, Levodopa equivalent doses, Hoehn-Yahr scale scores, MDS-UPDRS 3 and 4 scores, and scores of the third item of Freezing of Gait Questionnaire. Although prospective studies in the literature showed that freezing $(7,8)$ and disease severity $(40)$ posed a risk for falling, no such difference was found in our study. It was thought that the reason for this was that the patient group Table 2. Results on univariate logistic regression models of variables that are thought to be related to falls within six months

\begin{tabular}{|c|c|c|c|c|}
\hline Variables & $\mathrm{p}$ & $-2-\log$ likelihood value & $\operatorname{Exp}(B)$ & $95 \% \mathrm{CI}$ \\
\hline Previous history of falling & 0.716 & -7.338 & 2.368 & $0.23-245.01$ \\
\hline MDS-UPDRS 1.A & 0.190 & -8.245 & 0.687 & $0.392-1.20$ \\
\hline MDS-UPDRS 1.B & 0.104 & -11.408 & 3.896 & $0.756-20.07$ \\
\hline MDS-UPDRS 2 & 0.393 & -7.675 & 1.251 & $0.748-2.09$ \\
\hline 10MWT speed $(\mathrm{m} / \mathrm{s})$ & 0.165 & -10.391 & 0.552 & $0.238-1.28$ \\
\hline 10MWT+memory speed $(\mathrm{m} / \mathrm{s})$ & 0.471 & -7.562 & 1.389 & $0.569-3.39$ \\
\hline 10MWT+digit span-forwards speed $(\mathrm{m} / \mathrm{s})$ & 0.876 & -7.282 & 0.954 & $0.527-1.73$ \\
\hline 10MWT + digit span-backwards speed $(\mathrm{m} / \mathrm{s})$ & 0.428 & -7.667 & 0.836 & $0.537-1.30$ \\
\hline $10 \mathrm{MWT}+(100-7)$ speed $(\mathrm{m} / \mathrm{s})$ & 0.611 & -7.415 & 1.115 & $0.732-1.70$ \\
\hline
\end{tabular}

Table 3. The optimal multivariate logistic regression model result obtained using the backward elimination method based on probability ratio test statistics from stepwise selection methods, covering variables thought to be related with falls within six months

\begin{tabular}{|lllll} 
Variables & $\mathrm{p}$ & $-2-\log$ likelihood value & Exp (B) & 95\% CI \\
MDS-UPDRS 1.B & 0.016 & -17.503 & 2.064 & $1.143-3.726$ \\
10MWT speed (m/s) & 0.014 & -16.790 & 0.756 & $0.605-0.944$ \\
Exp (B): Relative Odds Ratio, CI: Confidence Interval, MDS-UPDRS: The Movement Disorder Society Unified Parkinson's Disease Rating scale, 10MWT: 10-Meter Walk test
\end{tabular}


consisted of relatively young patients with mild-to-moderatestage disease without cognitive impairment and frequent freezing. Although there was no difference in terms of motor findings and disease severity, there was a significant difference between the two groups in terms of previous history of falls. In many studies, it was emphasized that the history of previous falls $(1,2,8)$ could predict falling. Patients with cognitive impairment were not included in the study in order to complete cognitive dual tasks and because of the fact that cognitive dysfunction is a known risk factor for falling $(8,15)$. It was thought that the reason for the lack of differences in terms of MoCA scores between the two groups was due to this study protocol.

The 10MWT, which has been widely used and recommended for this purpose, was used to measure the walking speed of the patients (22). In our study, the mean time to complete the 10MWT in our patients in both groups remained below the cut-off value $(1.2 \mathrm{~m} / \mathrm{sec})$ indicating the risk of falling in PD (9). In the study by Paker et al. (40), a significant relationship was found between the deceleration of walking speed measured using 10MWT and the history of falling and the risk of falling. Similar findings were found in our study, and it was observed that an increase in walking speed decreased the risk of falling within six months by 0.76 times. In a recent study, it was observed that patients with PD, who had previously fallen, had lower walking speeds in both single and dual-task activities, but the most important methodologic disadvantage of the study was the evaluation of the last 6 months as the data of falling (13).

In a review by Fasano et al. (6), a second task added to walking was reported to be one of the risk factors of PD-related falls. For this reason, in our study, walking evaluations were made using dual task activities consisting of different cognitive loads. Although we found that different cognitive loads slowed the walking speed more in patients with a history of falling, it was shown that any cognitive load was not an independent risk factor for falling. This result was associated with patients' normal cognitive states.

There are a limited number of studies in the literature investigating the relationship between non-motor findings other than cognitive impairment and risk of falling. In the study by Paker et al. (40), a significant relationship was found between mood disorders such as anxiety and depression and the risk of falling. In our study, although anxiety and depression were not evaluated separately, the MDS-UPDRS part 1.A score in which these were questioned differed in both groups. Spindler et al. (18) reported that patients with PD with daytime sleepiness had a $20 \%$ higher risk of falling. Among the autonomic findings, orthostatic hypotension has been among the general risk factors, has been investigated in PD in a small number of studies, and has not been found as an independent risk factor alone $(8,19)$. Urinary incontinence has been found to be an important risk factor for falling in both the geriatric population and patients with PD $(3,20)$. In our study, the MDS-UPDRS part $1 . B$ score, in which these findings were questioned, differed in both groups, and it was seen that the increase in the score increased the risk of falling 2 times, independent of other variables.

The most important limitation of this study is the low number of patients and the short follow-up period. Another limitation is that non-motor findings are not examined with detailed scales. The strength of our study is that it is a prospective study performed to evaluate many possible risk factors for falling. In addition, a relatively homogeneous group was formed and attention was paid to the risk of falling in patients with mild-to-moderate-stage PD.

\section{Conclusion}

Falling in PD, where motor and non-motor findings are seen together, can be seen at every stage of the disease, and is one of the most important causes of morbidity. Today, not all risk factors of falling and preventive methods against falling have been determined. In our study, where all known risk factors were analyzed together in patients with mild-moderate stage PD without cognitive impairment, it was shown that along with walking speed, the MDS-UPDRS part $1 . \mathrm{B}$ score in which non-motor findings including sleep, and sensory and autonomic disturbances were evaluated together, predicted the risk of falling. In order to support these findings, studies with a larger patient population and longer follow-up are needed.

\section{Ethics}

Ethics Committee Approval: Istanbul Medipol University, Non-Interventional Clinical Research Ethics Committee (date: 23.12.2015).

Informed Consent: Informed consent form was obtained from all participants.

Peer-review: Externally peer-reviewed.

\section{Authorship Contributions}

Concept: Z.T., B.E.H., Design: Z.T., B.E.H., Data Collection or Processing: Z.T., B.E.H, E.Z., B.B., H.G., H.H., Analysis or Interpretation: Z.T., B.E.H., E.Z., H.H., Literature Search: Z.T., B.E.H., E.Z., Writing: Z.T., B.E.H., E.Z.

Conflict of Interest: No conflict of interest was declared by the authors.

Financial Disclosure: This work was supported by Istanbul University Scientific Research Projects Unit

\section{References}

1. Wood BH, Bilclough JA, Bowron A, Walker RW. Incidence and prediction of falls in Parkinson's disease: a prospective multidisciplinary study. J Neurol Neurosurg Psychiatry 2002;72:721-725.

2. Pickering RM, Grimbergen YAM, Rigney U, et al. A meta-analysis of six prospective studies of falling in Parkinson's disease. Mov Disord 2007;22:1892-1900

3. Balash Y, Peretz C, Leibovich G, Herman T, Hausdorff JM, Giladi N. Falls in outpatients with Parkinson's disease: frequency, impact and identifying factors. J Neurol 2005;252:1310-1315.

4. Fasano A, Plotnik M, Bove F, Berardelli A. The neurobiology of falls. Neurol Sci 2012;33:1215-1223.

5. Van der Marck MA, Klok MP, Okun MS, et al. Consensus-based clinical practice recommendations for the examination and management of falls in patients with Parkinson's disease. Parkinsonism Relat Disord 2014;20:360369.

6. Fasano A, Canning CG, Hausdorff JM, Lord S, Rochester L. Falls in Parkinson's disease: A complex and evolving picture. Mov Disord 2017;32:1-13.

7. Kerr GK, Worringham CJ, Cole MH, Lacherez PF, Wood JM, Silburn PA. Predictors of future falls in Parkinson's disease. Neurology 2010;75:116124.

8. Latt MD, Lord SR, Morris JGL, Fung VSC. Clinical and physiological assessments for elucidating falls risk in Parkinson's disease. Mov Disord 2009;24:1280-1289 
9. Paul SS, Canning CG, Sherrington C, Lord SR, Close JC, Fung VS. Three simple clinical tests to accurately predict falls in people with Parkinson's disease. Mov Disord 2013;28:655-662.

10. Wu T, Hallett M. Neural correlates of dual task performance in patients with Parkinson's disease. J Neurol Neurosurg Psychiatry 2008;79:760-766.

11. Brown RG, Marsden CD. Dual task performance and processing resources in normal subjects and patients with Parkinson's disease. Brain 1991;114:215231.

12. Wu T, Hallett M, Chan P. Motor automaticity in Parkinson's disease. Neurobiol Dis 2015;82:226-234.

13. Vance RC, Healy DG, Galvin R, French HP. Dual tasking with the timed "up \& go" test improves detection of risk of falls in people with Parkinson disease. Phys Ther 2015;95:95-102.

14. Zirek E, Ersoz Huseyinsinoglu B, Tufekcioglu Z, Bilgic B, Hanagasi H. Which cognitive dual-task walking causes most interference on the Timed Up and Go test in Parkinson's disease: a controlled study. Neurol Sci 2018;39:2151-2157.

15. Paul SS, Sherrington C, Canning CG, Fung VS, Close JC, Lord SR. The relative contribution of physical and cognitive fall risk factors in people with Parkinson's disease: a large prospective cohort study. Neurorehabil Neural Repair 2014;28:282-290.

16. Pasman EP, Murnaghan CD, Bloem BR, Carpenter MG. Balance problems with Parkinson's disease: are they anxiety-dependent? Neuroscience 2011;177:283-291.

17. Gazibara T, Kisic Tepavcevic D, Svetel M, et al. Near-falls in people with Parkinson's disease: Circumstances, contributing factors and association with falling. Clin Neurol Neurosurg 2017;161:51-55.

18. Spindler M, Gooneratne NS, Siderowf A, Duda JE, Cantor C, Dahodwala N. Daytime sleepiness is associated with falls in Parkinson's disease. J Parkinsons Dis 2013;3:387-391.

19. Gray P, Hildebrand K. Fall risk factors in Parkinson's disease. J Neurosci Nurs 2000;32:222-228.

20. Foley AL, Loharuka S, Barrett JA, et al. Association between the Geriatric Giants of urinary incontinence and falls in older people using data from the Leicestershire MRC Incontinence Study. Age Ageing 2012;41:35-40.

21. Hulbert S, Rochester L, Nieuwboer A, et al. "Staying safe"- a narrative review of falls prevention in people with Parkinson's - "PDSAFE". Disabil Rehabil 2019;41:2596-2605.

22. Bloem BR, Marinus J, Almeida Q, et al. Measurement instruments to assess posture, gait, and balance in Parkinson's disease: Critique and recommendations. Mov Disord 2016;31:1343-1355.

23. Hughes AJ, Daniel SE, Kilford L, Lees AJ. Accuracy of clinical diagnosis of idiopathic Parkinson's disease: a clinico-pathological study of 100 cases. J Neurol Neurosurg Psychiatry 1992;55:181-184.

24. Nasreddine ZS, Phillips NA, Bédirian V, et al. The Montreal Cognitive Assessment, MoCA: a brief screening tool for mild cognitive impairment. J Am Geriatr Soc 2005;53:695-659.
25. Ozdilek B, Kenangil G. Validation of the Turkish Version of the Montreal Cognitive Assessment Scale (MoCA-TR) in patients with Parkinson's disease. Clin Neuropsychol 2014;28:333-343.

26. Giladi N, Shabtai H, Simon ES, Biran S, Tal J, Korczyn AD. Construction of freezing of gait questionnaire for patients with Parkinsonism. Parkinsonism Relat Disord 2000;6:165-170.

27. Acaröz Candan S, Çatıker A, Özcan TŞ. Psychometric properties of the Turkish version of the freezing of gait questionnaire for patients with Parkinson's disease. Neurol Sci Neurophysiol 2019;36:44-50.

28. Duncan PW, Weiner DK, Chandler J, Studenski S. Functional reach: a new clinical measure of balance. J Gerontol 1990;45:M192-197.

29. Dibble LE, Lange M. Predicting falls in individuals with Parkinson disease: a reconsideration of clinical balance measures. J Neurol Phys Ther 2006;30:6067.

30. Tomlinson CL, Stowe R, Patel S, Rick C, Gray R, Clarke CE. Systematic review of levodopa dose equivalency reporting in Parkinson's disease. Mov Disord 2010;25:2649-2653.

31. Moore O, Peretz C, Giladi N. Freezing of gait affects quality of life of peoples with Parkinson's disease beyond its relationships with mobility and gait. Mov Disord 2007;22:2192-2195.

32. Akbostanci MC, Bayram E, Yilmaz V, et al. Turkish Standardization of Movement Disorders Society Unified Parkinson's Disease Rating Scale and Unified Dyskinesia Rating Scale. Mov Disord Clin Pract 2017;5:54-59.

33. Medijainen K, Pääsuke M, Lukmann A, Taba P. Functional Performance and Associations between Performance Tests and Neurological Assessment Differ in Men and Women with Parkinson's Disease. Behav Neurol 2015;2015:519801.

34. Brusse KJ, Zimdars S, Zalewski KR, Steffen TM. Testing functional performance in people with Parkinson disease. Phys Ther 2005;85:134-141.

35. Mickey RM, Greenland S. The impact of confounder selection criteria on effect estimation. Am J Epidemiol 1989;129:125-137.

36. Voss TS, Elm JJ, Wielinski CL, et al. Fall frequency and risk assessment in early Parkinson's disease. Parkinsonism Relat Disord 2012;18:837-841.

37. Nyström H, Nordström A, Nordström P. Risk of Injurious Fall and Hip Fracture up to 26 y before the Diagnosis of Parkinson Disease: Nested CaseControl Studies in a Nationwide Cohort. PLoS Med 2016;13:e1001954.

38. Lord S, Galna B, Yarnall AJ, Coleman S, Burn D, Rochester L. Predicting first fall in newly diagnosed Parkinson's disease: Insights from a fall-naïve cohort. Mov Disord 2016;31:1829-1836.

39. Herold F, Hamacher D, Schega L, Müller NG. Thinking While Moving or Moving While Thinking - Concepts of Motor-Cognitive Training for Cognitive Performance Enhancement. Front Aging Neurosci 2018;10:228.

40. Paker N, Bugdayci D, Goksenoglu G, Demircioğlu DT, Kesiktas N, Ince $\mathrm{N}$. Gait speed and related factors in Parkinson's disease. J Phys Ther Sci 2015;27:3675-3679. 